\title{
Investigating Factors for Knowledge Sharing Using Web Technologies
}

\author{
Hanan Alotaibi \\ University of Southampton, UK \\ hmqa1g09@ecs.soton.ac.uk
}

\author{
Richard Crowder \\ University of Southampton, UK \\ rmc@ecs.soton.ac.uk
}

\author{
Gary Wills \\ University of Southampton, UK \\ gbw@ecs.soton.ac.uk
}

\begin{abstract}
Global knowledge has become a central issue for an organization's survival. In the last few decades, Web technologies have become widely used for Knowledge Management; these are called Knowledge Management Systems (KMS). Recently, in Knowledge Management (KM) the effectiveness of knowledge sharing has been considered a significant component for KMS success. In the most universities the KM is often inadequate when it comes to knowledge sharing, especially between academics. In order to encourage knowledge sharing, it is important to know why/where/when academics choose to contribute or to receive shared knowledge. Therefore, the purpose of this research is to investigate the factors that affect an academics' behavior towards knowledge sharing by using technology. Knowledge Sharing Technology model (KST) is proposed model was constructed combining the affecting factors: these factors are a synthesis of factors which already exist in current theories, i.e. the Unified Theory of Acceptance and Use of Technology (UTAUT) and Social Exchange Model (SET), as well as other factors which are always explored independently in research studies The future work will focus on confirming the model.
\end{abstract}

\section{Categories and Subject Descriptors}

H.1.1 Systems and Information Theory, H.1.2 User/Machine Systems, Human factors.

\section{General Terms}

Theory, Human Factors, Management.

\section{Keywords}

Knowledge management, Universities, Knowledge sharing Technology, Academics

Permission to make digital or hard copies of part or all of this work for personal or classroom use is granted without fee provided that copies are not made or distributed for profit or commercial advantage and that copies bear this notice and the full citation on the first page. Copyrights for thirdparty components of this work must be honored. For all other uses, contact the Owner/Author.

Copyright is held by the owner/author(s).

i-Know '13, Sep 04-06 2013, Graz, Austria

ACM 978-1-4503-2300-0/13/09.

http://dx.doi.org/10.1145/2494188.2494230

\section{INTRODUCTION}

According to [1], $80 \%$ of the largest global corporations now have knowledge management projects to support their development and growth. Therefore, organizations include higher education institutions and universities, would benefit from establishing appropriate knowledge management system to be successful places. The general activities in knowledge management [2] are acquiring, sharing, and storing the knowledge the most crucial activity of all is knowledge sharing since most knowledge is held as tacit knowledge by people [3]. However, knowledge management in higher education is often inadequate when it comes to knowledge sharing, especially between academics [4]. In higher education novices are academics, who are new discipline in the university, new to teaching or new to a specific university, while experts academics are those who have experience at teaching at a specific university. This paper identifies the problem in KM field in Universities and Institutions, and provides the constructed model of Knowledge Sharing Technology, and the future of this research.

\section{RESEARCH PROBLEM IDENTIFICATION}

Sharing knowledge via web technology, such as Wiki or Blogs, between academics could be between experts and novices, employees who do not have experience, or between experts. Tacit knowledge (Knowledge inside expert's head) from expert academics is often lost as the knowledge has not been made explicit (codified). Thus, the novices academic are unable to capture valuable information while there is no knowledge share mechanism between academic staffs, this can affect academic performance, so this may result in a poorer student experience and lower academic achievement.

There is insufficient of the study's dependence on the academics perspective on knowledge sharing and knowledge cultures [5] and studies on knowledge sharing technology of academics in higher education have not yet been conducted. Thus, this study is the first to examine academics' behavior toward knowledge sharing using web technology.

\section{RESEARCH OBJECTIVES}

The aim of this research is to investigate factors that influence academics' behavior toward knowledge sharing via web technology. Hence the research questions are:

1. What are the significant factors that increase the use of knowledge share via web technology?

2. What are barriers of sharing individual knowledge among web technologies?

3. What is academics' attitude toward knowledge sharing via web technologies? 
To aid the investigation of these questions, a model of the factors effecting knowledge sharing technology has been constructed including the synthesis of affecting factors; some factors that already exist in the theories UTAUT [6] and SET [7], and other factors , such trust, time, leadership and IT support, that are always explored independently in research [8,9,10 and 11].

\section{RESEARCH MODEL}

The research model is constructed in order to examine academic staffs' behavior toward sharing knowledge and the technology used to share this knowledge. Using theoretical frameworks UTAUT and SET to underpin the model and using existing research into knowledge management, the model has been constructed by combining, synthesizing and refactoring the factors, which have the most important effects in knowledge sharing using web technologies. A Knowledge Sharing Technology Model presents in Figure 1 (read it from left to right). Also, Table 1 identifies factors involved in the model and provides the supportive theories for these factors. The details of KST model will be presented next sections.

\subsection{Motivation}

In academic life, the big issues facing staff are difficulties in sharing knowledge because of lack of time for preparing the subject to be presented and the fact that knowledge sharing activities require a high level of effort [12]. In this case, the academic staff should be encouraged to engage in knowledge sharing activities, and it is also unrealistic to assume that all staff contributes their knowledge. In fact, human beings will offer their knowledge when they expect reward, such as extra payment [13]. Also, in the case of the benefit expected from knowledge sharing, the benefit is not only more payment but also reciprocal benefit.

There are some employees who contribute their knowledge because of their belief in their self-abilities and competences, and also the belief that their knowledge can help to work improvements; this is a self-efficiency factor. Furthermore, work experience drives staff towards knowledge sharing in order to obtain satisfaction and pleasure [13]. Some individuals enjoy helping others, especially if they are working in group [14].

It can be assumed that employees' attitudes towards knowledge sharing are dependent on intrinsic and extrinsic motivation. Intrinsic motivation includes expected reward and reciprocal benefit, and extrinsic motivation includes self-efficiency, work experience and enjoying helping others. Furthermore, extracting and refactoring the construction of expectancy performance in the UTAUT model constructs a model adapted to the academics process.

\subsection{Technology Acceptance}

TAM is the most widely applied model of user acceptance and usage [15]. Many studies on different aspects have used the TAM as a framework to investigate factors influencing knowledge sharing through management systems, for example [16]. By examining two factors that influence individual attitude, perceived usefulness and perceived ease of use they have shown evidence that these factors are strongly correlated with attitude towards the acceptance of information technology. When staff feel the technologies can be used in an easy way, it is more probable that they will present their knowledge. So their attitude to ease of use will affect an individual's knowledge sharing behavior. Also staffs are more likely to share their knowledge when they feel that they have worthwhile information that is very useful for other staff. Therefore, both these factors have been selected in the model to examine the effect of academics attitudes towards knowledge sharing technologies

\subsection{Organizational Culture}

Organizational culture has a relationship with staff's communication and knowledge sharing behavior, as previous research has pointed out [17]. Most of studies [17] and [18] have suggested that organizations should create opportunities for employees' interaction and facilitates of knowledge sharing.

According to SET, trust has an indirect influence on knowledge sharing, which leads to increased sharing through technology. Furthermore, other researchers have examined affect-based trust and cognition-based trust [19] and [20], and found that trust has an effect on sharing knowledge when staff believe other team members are honest.

Other factor is time, in $[8,9]$ examined the influences of time on knowledge share, and found that the most staff unwilling to share their knowledge because of lack of time. Moreover, in [21] claims that time is one of the barriers to knowledge sharing in organizations, as adding information to the system is time consuming. However, the author's opinion is that knowledge sharing is definitely time-saving, once the information is available in the system. Thus, staff can reach the valuable information that has been previously placed in the system more quickly, rather than searching in the other huge sources. Also, time management is the principle of the knowledge management approach to sharing appropriate knowledge.

Furthermore, leadership in a team setting has a strong relationship with knowledge sharing. According to [10], a team's expertise is more highly developed when there is a leader controlling the team in regard to knowledge sharing and moreover, providing a good quality of new ideas and encouraging staff to share their knowledge. So, leadership has an influence on employee's attitude toward knowledge sharing by using technology. The writer believes that the leadership has a significant influence in the Saudi universities' situation (different campuses and separate male and female sections).

Finally, IT support has direct assistance in the processes and circumstances to create knowledge [11]. The success of KM is commonly based on implementation of new IT-based systems. Staff codifying and sharing knowledge by a system are required to be familiar with using the system or there is assistance for users who are unfamiliar with IT. In addition, among the fast growing technologies, the changing tools of the system there is continual improvement, so users should be kept up-to-date with new changes. Therefore, it is crucial that knowledge technicians then the users will find the technologies easy to use. Easy use of the system will enhance knowledge sharing through web technologies. Therefore, in the writer's opinion, IT support will encourage IT acceptance. 


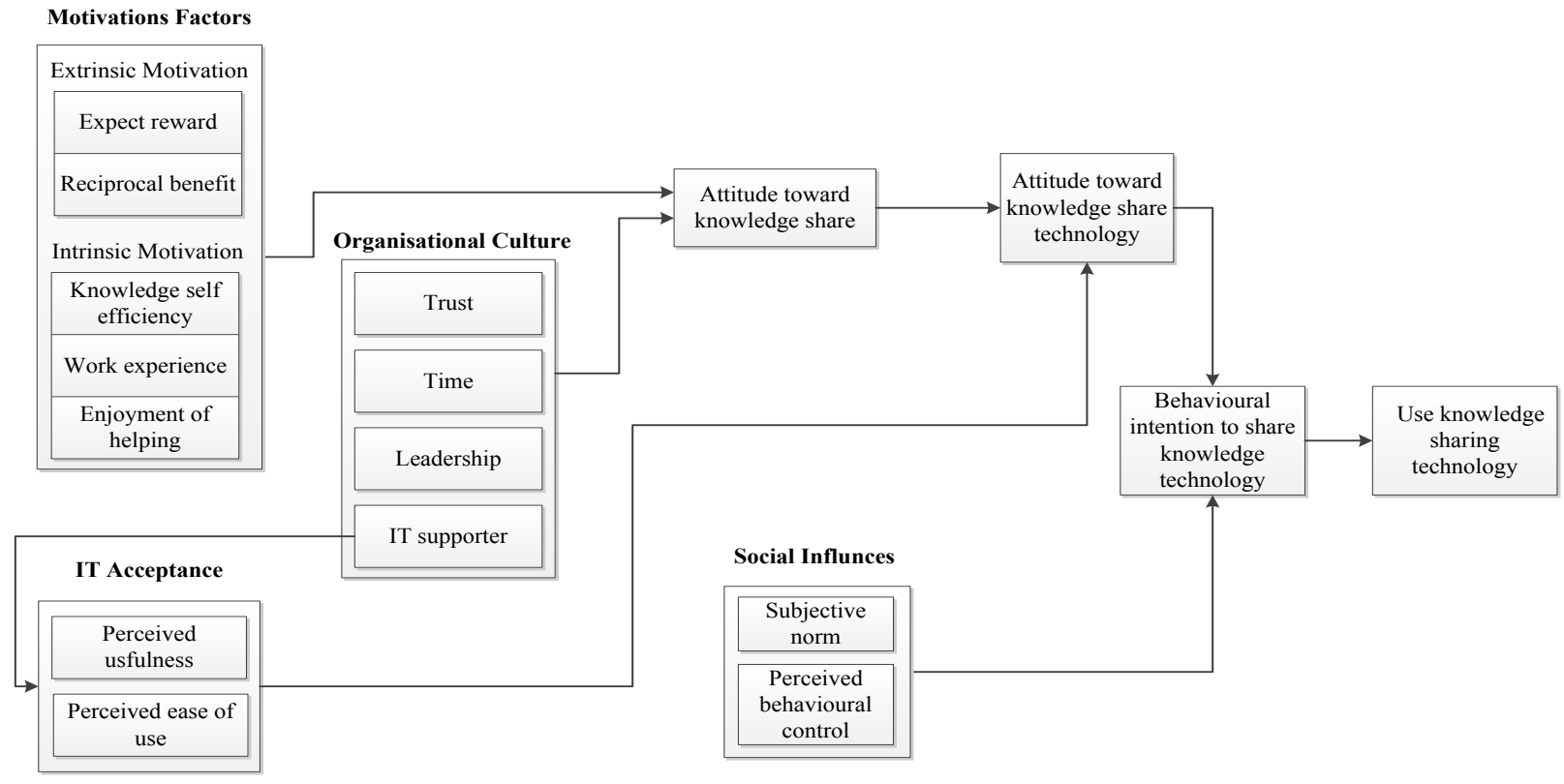

Figure 1 Knowledge Sharing Technology Model

Table 1 The factors identified for inclusion in the model

\begin{tabular}{|c|c|c|c|}
\hline Factors & Sub-Dimensions & $\begin{array}{l}\text { Theories and } \\
\text { References }\end{array}$ & Definition \\
\hline \multirow[t]{2}{*}{ Extrinsic motivation } & Expected Reward & \multirow[t]{2}{*}{ UTAUT } & \multirow{2}{*}{$\begin{array}{l}\text { The staff will share knowledge because he expect to obtain } \\
\text { valuable outcomes }\end{array}$} \\
\hline & Reciprocal benefit & & \\
\hline \multirow[t]{3}{*}{ Intrinsic motivation } & Self-efficiency & UTAUT & \multirow{3}{*}{$\begin{array}{l}\text { The staff will share knowledge because he believe that he have } \\
\text { valuable information that should be shared }\end{array}$} \\
\hline & Work experience & UTAUT & \\
\hline & $\begin{array}{l}\text { Enjoyment } \\
\text { helping other }\end{array}$ & UTAUT & \\
\hline \multirow[t]{2}{*}{ Acceptance } & $\begin{array}{l}\text { Perceived } \\
\text { usefulness }\end{array}$ & UTAUT & $\begin{array}{l}\text { The degree to which staff believes that using particular system } \\
\text { would be enhanced to share knowledge }\end{array}$ \\
\hline & $\begin{array}{l}\text { Perceived ease of } \\
\text { use }\end{array}$ & UTAUT & $\begin{array}{l}\text { The degree to which staff believes that using particular system } \\
\text { would be free of effort to share knowledge }\end{array}$ \\
\hline \multirow[t]{2}{*}{ Social Influences } & Subjective norm & UTAUT & $\begin{array}{l}\text { the degree to which a staff perceives whether social pressure } \\
\text { will affect the performance of knowledge sharing technology }\end{array}$ \\
\hline & $\begin{array}{l}\text { Perceived } \\
\text { behavioral control }\end{array}$ & UTAUT & $\begin{array}{l}\text { The degree to which a staff perceives the ease or the difficulty } \\
\text { of performing knowledge sharing behavior }\end{array}$ \\
\hline \multirow[t]{4}{*}{$\begin{array}{l}\text { Organizational } \\
\text { Culture }\end{array}$} & Trust & SET & $\begin{array}{l}\text { The degree of staff 's believe that other members are honest } \\
\text { and have valuable and useful knowledge to share }\end{array}$ \\
\hline & Time & [8] and [9] & $\begin{array}{l}\text { The staff believes that sharing knowledge is non-consuming } \\
\text { time while information is available on the system }\end{array}$ \\
\hline & Leadership & {$[10]$} & $\begin{array}{l}\text { The staff believe that leadership for members is enhanced to } \\
\text { encourage employees to share knowledge }\end{array}$ \\
\hline & IT Support & {$[11]$} & $\begin{array}{l}\text { The staff believe that Knowledge technicians support the } \\
\text { knowledge management service and its use }\end{array}$ \\
\hline
\end{tabular}




\section{RESEARCH METHODS}

A survey method will be used in the study; consisted of multiple phases. As a first step, in-depth interviews will be conducted with experts in $\mathrm{KM}$ in order to explore other unmentioned factors and investigate academics requirement toward knowledge sharing. Moreover, interviews with knowledge workers in some university to discover the usual knowledge infrastructure of the higher education, and the abilities and acceptance of academics in using systems in universities website and specify key categories of information or knowledge that the university would address.

After these pervious steps, analyzing of the finding and result will be undertaken to discover how the model could be improved to include more effecting factors. Finally, based on the previous stages an instrument questionnaire will be designed, and then explore the academics attitude toward knowledge sharing technology.

\section{DISCUSSION AND CONCLUSION}

The research objective is to improve knowledge management in higher education and to facilitate exchanging knowledge between academics. Therefore, this study will explore the effective factors of knowledge sharing using web technology by examining academic staff's behavior toward knowledge sharing. After analysis, synthesis and refactoring of the factors from literature and theories a framework was constructed so the first question is partly has been answered. After the pilot test will be conducted in order to discover how the model would be improved.

\section{ACKNOWLEDGMENTS}

This research was initiated by Electronic and Computer Science researchers at University of Southampton.

\section{REFERENCES}

[1] J. Brown and P. Duguid. "Knowledge and Organisation: A Social-practice Perspective." Organisation Science, 198-213, 2001.

[2] N. Milton, N. Shadbolt, H. Cottam and M. "Hammersley.. Towards Knowledge Technology for Knowledge Management." Human-Computer Studies, 1999.

[3] I. Nonaka and H. Takeuchi. The knowledge-creating company: How Japanese companies create the dynamics of innovation. USA, Oxford University Press, 1995. pp 96-104.

[4] H. Lin. "Effect of extrinsic and intrinsic motivation on employee knowledge sharing intentions." Journal of Information Science, vol 33 (2), 135-149, 2007.

[5] R. Fullwood, J. Rowley and R. Delbridge. "Knowledge sharing amongst academics in UK universities." Journal of Knowledge Management, vol. 17, pp.123 - 136, 2013.

[6] V. Venkatesh, M. Morris, G. Davis and F. Davis F. "User Acceptance of Information Technology toward a Unified View." MIS Quarterly, vol. 27 (3), pp. 425-478 2003.

[7] P. Blau. Exchange and Power in Social Life. New York: Wiley1964.
[8] D. Ford and Y. Chan. "Knowledge sharing in a multi-cultural setting: A case study." Knowledge Management Research \& Practice, vol. 4, pp. 3-16 2003.

[9] D. Ford and D. Staples. "Perceived Value of Knowledge: The potential informer's perception.” Knowledge Management Research \& Practice, vol. 4, pp. 3-16, 2006.

[10] G. Bain, L. Mann, L. Atkins and J. Dunning. "R\&D Project Leaders: Roles and Responsibilities." Leadership, Management, and Innovation in R\&D Project Teams, pp. 49-702005.

[11] B. Bergeron. Essentials of Knowledge Management New Jersey. USA, 2003.

[12] K. Husted, S. Michailova, D. Minbaeva. Knowledge sharing and organizational performances: the role of extrinsic and intrinsic motives. Cairns Australia. 2005.

[13] H. Lin. "Effect of extrinsic and intrinsic motivation on employee knowledge sharing intentions." Journal of Information Science, vol 33 (2), pp. 135-1492007.

[14] I. Emmerik, I. Jawahar. "Lending a helping hand, provision of helping behavior beyond professional career responsibilities." Career Development International, vol 5, p. 10, 2005.

[15] F. Davis, R. Bagozzi, and P. Warshaw, "User Acceptance of Computer Technology: A Comparison of Two Theoretical Models.” Management Science, vol (35:8), pp. 982-1003.1989

[16] P. Lin, F. Chen and H. Qin. "Research of Blog Based Knowledge Management System of Architectural Design Companies." Wuhan, China, Second International Symposium on Knowledge Acquisition and Modeling. 2009.

[17] I. Nonaka, and H. Takeuchi.. The knowledge-creating company: How Japanese companies create the dynamics of innovation. USA, Oxford University Press. 1995.

[18] C. Yang, and C. L. "Can organizational knowledge capabilities affect knowledge sharing behavior?" Journal of Information Science, vol 33(1), p. 95-109. 2007

[19] S. Chowdhury.. "The role of affect- and cognition-based trust in complex knowledge sharing." Journal of Managerial Issues, vol 17(3), p. 310-326, 2005.

[20] T. Mooradian, B. Renzl and K. Matzler. "Who trusts? Personality, trust and knowledge sharing." Management Learning, vol 37(4), p. 523-540, 2006.

[21] T. Haldin-Herrgard. "Difficulties in diffusion of tacit knowledge in organizations." Journal of Intellectual Capital, vol 1, pp. 357-365, 2000. 